\title{
Hybrid Surgical Repair for Recurrent Coarctation of the Transvers Arch: Case Report
}

\author{
Kıvanc ATILGAN ${ }^{1}$, Alper TOSYA ${ }^{2}$, Fahri YEŞIL ${ }^{3}$, Pinar Koksal Coskun ${ }^{4}$, Burak ONUK ${ }^{3}$, \\ and Tayfun Aybek ${ }^{4}$ \\ ${ }^{1}$ Gulhane Military Medical Academy, School of Medicine \\ ${ }^{2}$ Koç University Graduate School of Health Sciences \\ ${ }^{3}$ TOBB ETU Hospital \\ ${ }^{4}$ TOBB-ETU Hospital
}

July 10, 2021

\begin{abstract}
The incidence of postoperative recurrent coarctation of the aorta ranges from $5 \%$ to $50 \%$, and largely depends on the age at initial repair. Due to the increased fibrosity and rigidity of the aorta in older age, stent placement is preferred instead of balloon angioplasty, resulting in an almost complete relief of the gradient in $>95 \%$ of the patients. In patients with transverse arch hypoplasia, transcatheter intervention with further surgical intervention may be needed, and the use of stenting was shown to be effective in the treatment of patients with hypoplastic isthmus, arch or tubular coarctation. In this case of a late re-coarctation, we preferred to apply a hybrid technique for treatment. The first step of the treatment was debranching of the brachiocephalic and left common carotid arteries with upper mini median sternotomy. On the following day, the patient underwent a successful stent placement to the transvers arch.
\end{abstract}

Title: Hybrid Surgical Repair for Recurrent Coarctation of the Transvers Arch: Case Report

Short Title: Hybrid Surgery of Recurrent Coarctation

\section{Authors:}

1. Dr. Kıvanç ATILGAN

Institution: TOBB ETU Hospital Carrdiovascular Surgery Department, Ankara

Address: Beştepe Mah. Yaşam Cad. No:5 TOBB ETU HastanesiYenimahalle/ANKARA

Phone number: +905056579890

E-mail: kivancatilgan@gmail.com

ORCID: 0000-0001-9907-9879

2. Dr. Alper İbrahim TOSYA

Institution: TOBB ETU Hospital Carrdiovascular Surgery Department, Ankara

Address: Beştepe Mah. Yaşam Cad. No:5 TOBB ETU HastanesiYenimahalle/ANKARA

Phone number: +905304604160

E-mail: alpertosya@yahoo.com 
ORCID: 0000-0002-0195-9032

3. Dr. Fahri Gürkan YEŞİL

Institution: TOBB ETU Hospital Carrdiovascular Surgery Department, Ankara

Address: Beştepe Mah. Yaşam Cad. No:5 TOBB ETU HastanesiYenimahalle/ANKARA

Phone number: +905077603021

E-mail: gurkanyesil@hotmail.com

ORCID: 0000-0001-7816-4193

4. Dr. Pınar KÖKSAL COŞKUN

Institution: TOBB ETU Hospital Carrdiovascular Surgery Department, Ankara

Address: Beştepe Mah. Yaşam Cad. No:5 TOBB ETU HastanesiYenimahalle/ANKARA

Phone number: +905053191096

E-mail: koksal42@hotmail.com

ORCID: 0000-0002-4649-9834

\title{
5. Burak Emre ONUK
}

Institution: TOBB ETU Hospital Cardiovascular Surgery Department, Turkey

Address: Beştepe Mah. Yaşam Cad. No:5 TOBB ETU Hastanesi Yenimahalle/Ankara TURKEY

Phone number: +905325209745

E-mail:burakonuk@hotmail.com

ORCID: 0000-0003-3941-3622

6. Prof. Dr. Tayfun AYBEK

Institution: TOBB ETU Hospital Carrdiovascular Surgery Department, Ankara

Address: Beştepe Mah. Yaşam Cad. No:5 TOBB ETU HastanesiYenimahalle/ANKARA

Phone number: +905336994086

E-mail: ta@tayfunaybek.com

ORCID: 0000-0002-8565-6863

\begin{abstract}
The incidence of postoperative recurrent coarctation of the aorta ranges from $5 \%$ to $50 \%$, and largely depends on the age at initial repair. Due to the increased fibrosity and rigidity of the aorta in older age, stent placement is preferred instead of balloon angioplasty, resulting in an almost complete relief of the gradient in $>95 \%$ of the patients. In patients with transverse arch hypoplasia, transcatheter intervention with further surgical intervention may be needed, and the use of stenting was shown to be effective in the treatment of patients with hypoplastic isthmus, arch or tubular coarctation. In this case of a late re-coarctation, we preferred to apply a hybrid technique for treatment. The first step of the treatment was debranching of the brachiocephalic and left common carotid arteries with upper mini median sternotomy. On the following day, the patient underwent a successful stent placement to the transvers arch.
\end{abstract}

\section{Introduction}


The incidence of coarctation of aorta $(\mathrm{CoA})$ is 4 in 10,000 live births, and accounts for $5 \%$ to $8 \%$ of congenital heart diseases [1]. Patent ductus arteriosus, ventricular septal defect, bicuspid aortic valve, cerebral aneurysms of the circle of Willis and other congenital heart diseases (transposition of the great vessels, Tausig-Bing anomaly, hypoplastic left heart syndrome etc.) may accompany CoA [2,3]. In untreated cases, coronary disease, aortic dissection and rupture, cerebrovascular accident, or bacterial endocarditis may develop as complications, while the survival of these cases is approximately 35 years [4] and the majority of patients $(90 \%)$ die before their 50 s $[2,4]$.

After repair, postoperative persistent arterial hypertension occurs in $7 \%$ to $33 \%$ of patients and may be a result of recurrent or residual CoA, or may be idiopathic. The frequency of postoperative recurrent CoA ranges from $5 \%$ to $50 \%$. The significant variation in recurrence frequency is primarily associated with the age at initial repair $[9,10]$ rather than factors such as the specific surgical method of repair, suture material and sewing technique, which were once suggested to be associated with recurrence development [4].

\section{Case}

A 32-year-old male with a history of aortic coarctation repair operation, performed via posterolateral thoracotomy 17 years ago, was admitted to our hospital with a serious angina pectoris lasting for two months. On computerized tomography angiography of the thorax, a post-stenotic dilatation was observed in relation with a recurrent coarctation between the left carotid common carotid artery and the left subclavian artery (Figure 1). First, a debranching operation was carried out with a partial upper median sternotomy. The proximal part of a Dacron graft with a diameter of $14 / 7 \mathrm{~mm}$ was anastomosed to the ascending aorta and the distal parts were anastomosed to the brachiocephalic and left common carotid arteries (Figure 2). On the following day, a thoracic aorta stent with a diameter of $30 \times 30 \times 200 \mathrm{~mm}$ was implanted to the coarctated transvers arch (Figure 3, A and B).

\section{Discussion}

The first surgical repair of CoA was applied in 1944 [5]. Since then, surgical methods improved which resulted in extended survival of patients, and therefore, a greater number of patients with CoA reached adulthood. According to recent studies, the survival of patients operated at a median age of 16 years is $91 \%$ at 10 years, $84 \%$ at 20 years and $72 \%$ at 30 years after operation [6]. Although early diagnosis and treatment are paramount for improving outcomes, in cases with delayed diagnosis, repair of the aortic coarctation is still recommended at an older age, which results in improved blood pressure regulation and lower risk of cardiovascular events and improves survival. In more than $70 \%$ of the patients, death during the late period after treatment is the result of a cardiovascular complication [6].

Transcatheter treatment for aortic coarctation has recently become the treatment of choice due to its various technical advantages, including feasibility, relative safety, shorter hospitalization and fewer surgical complications. Due to the increased fibrosity and rigidity of the aorta in older age, stent placement is preferred instead of balloon angioplasty, an approach which has been shown to result in an almost complete relief of the gradient in $>95 \%$ of the patients [6].

Re-coarctation after surgery is observed in $44 \%$ of neonates and in $11 \%$ of older children, whereas the risk is lower but still relevant in adulthood (less than 9\%) [4,6]. About 9\% of surgically-treated patients can develop aneurysms or pseudo-aneurysms, while those treated with balloon dilatation carry a much higher risk (20\%). Additionally, individuals with coexisting bicuspid aortic valves are at an increased risk of developing aortic root dilatation [4].

For the treatment of recurrent aortic coarctation, primary balloon angioplasty with or without stent implantation has become the first-choice treatment. In the long-term, percutaneous balloon angioplasty for re-coarctation is accepted to be reliable; however, further surgical intervention or transcatheter intervention may be needed in patients with transverse arch hypoplasia, and the use of stenting is demonstrated to be effective in treating patients with hypoplastic isthmus, arch or tubular coarctation [6]. The operational technique should be determined with respect to the characteristics of each patient. While most patients 
with re-coarctation will usually be suitable candidates for transcatheter treatment, complex anatomy and/or cardiac comorbidities may favor a surgical approach or could warrant hybrid techniques [7].

In this case of a late re-coarctation, we preferred to apply a hybrid technique. Debranching the brachiocephalic and left common carotid arteries with upper mini median sternotomy was the first step of our treatment process. On the following day, the patient underwent a successful stent placement. The patient was discharged on the postoperative third day, without any complications.

\section{Conclusion}

Balloon angioplasty and stent placement in the treatment of re-coarctation cases have gained popularity and are applied safely in many health centers with experienced surgeons. However, in complicated cases, the utilization of hybrid techniques could benefit patients in both the short and long-term, due to decreased recurrence incidence.

\section{Conflict of Interests}

The authors declare that there are no conflict of interests.

\section{Ethics Statement}

This study was approved by the Institutional and Zonal Ethical Committee and the informed consent was taken from the patient in own language.

\section{References}

1. Hoffman JIE, Kaplan S. The incidence of congenital heart disease. J Am CollCardiol 2002;39:1880 -900 .

2. Chuter TA, Ivancev K, Lindblad B, Brunkwall J, Arén C, Risberg B. Endovascular stent-graft exclusion of an aortobronchial fistula. J VascIntervRadiol 1996;7:357-9

3. Léobon B, Roux D, Mugniot A, Rousseau H, Cérene A, Glock Y et al. Endovascular treatment of thoracic aortic fistulas. Ann ThoracSurg 2002;74:247-9.

4. Brown JW, Ruzmetov M, Hoyer MH, Rodefeld MD, Turrentine MW. Recurrent coarctation: is surgical repair of recurrent coarctation of the aorta safe and effective? Ann Thorac Surg. 2009 Dec;88(6):192330; discussion 1930-1. doi: 10.1016/j.athoracsur.2009.07.024.

5. Crafoord C, Nylin G. Congenital coarctation of the aorta and its surgical treatment. J ThoracCardiovascSurg 1945;14:347- 61.

6. Vriend JW, Mulder BJ. Late complications in patients after repair of aortic coarctation: implications for management. Int J Cardiol. 2005 Jun 8;101(3):399-406.

7. AttenhoferJost CH, Schaff HV, Connolly HM, et al. Spectrum of reoperations after repair of aortic coarctation: importance of an individualized approach because of coexistent cardiovascular disease. Mayo ClinProc 2002;77:646-53.

Figure 1. Preoperative CT image of CoA and diametric measurements.

Figure 2. Debranching of Brachiocephalic and Left Common Carotid Artery

Figure 3A. Angiographic image of debranching anastomosis (arrows)

Figure 3B. Angiographic image after stent implantation, debranching graft, brachiocephalic and left common carotid arteries are imaged with contrast (arrows) 


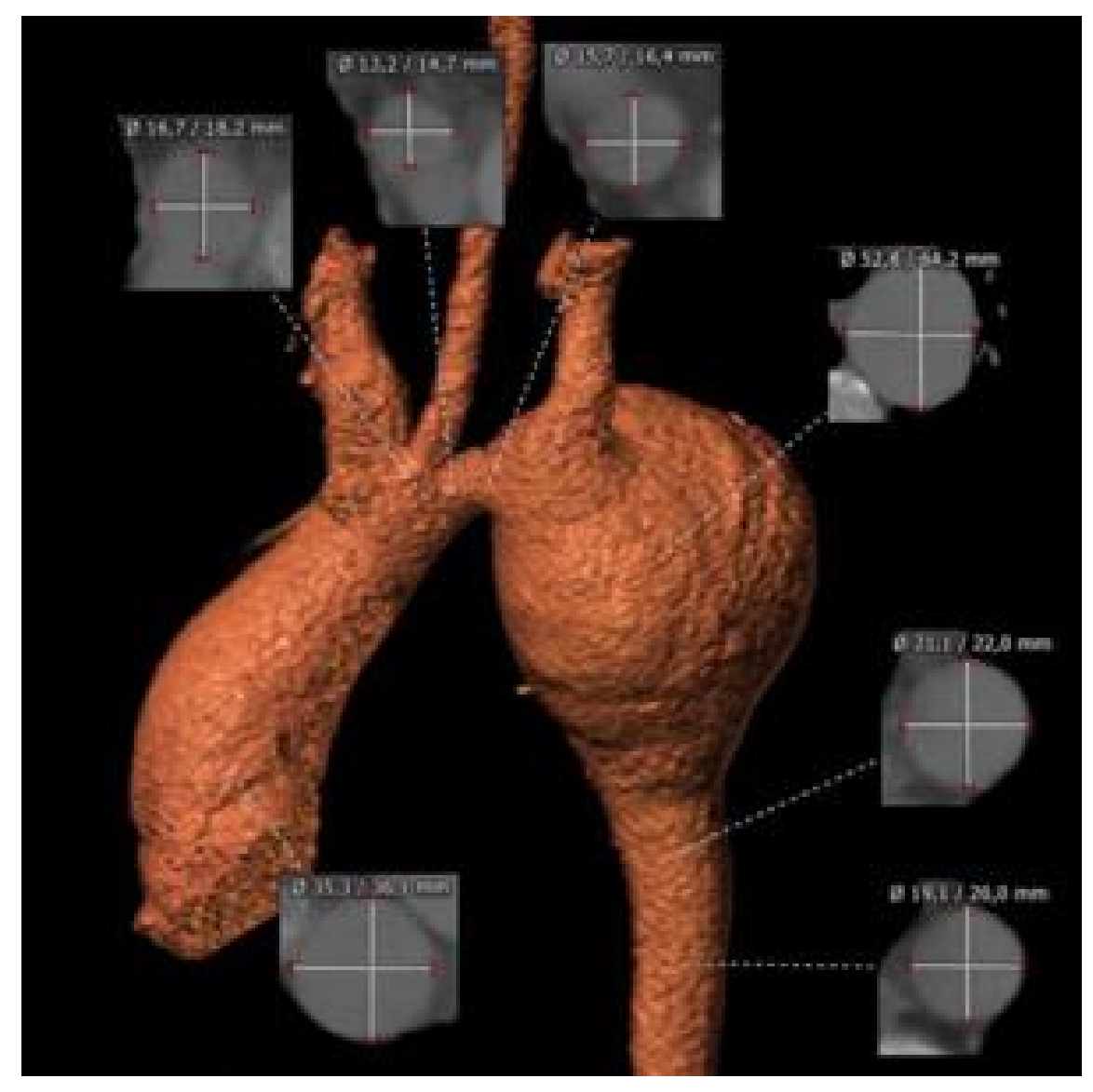




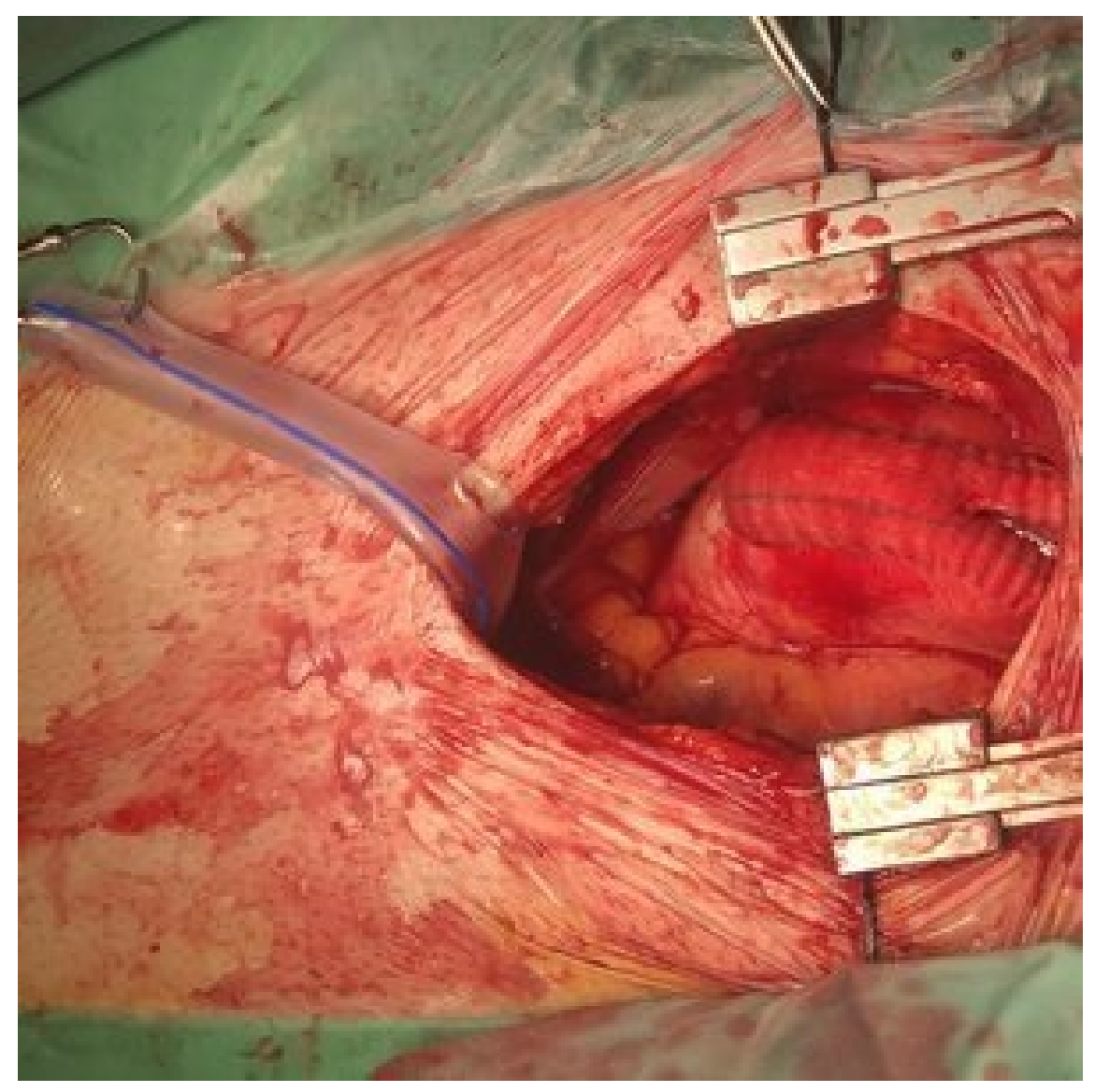





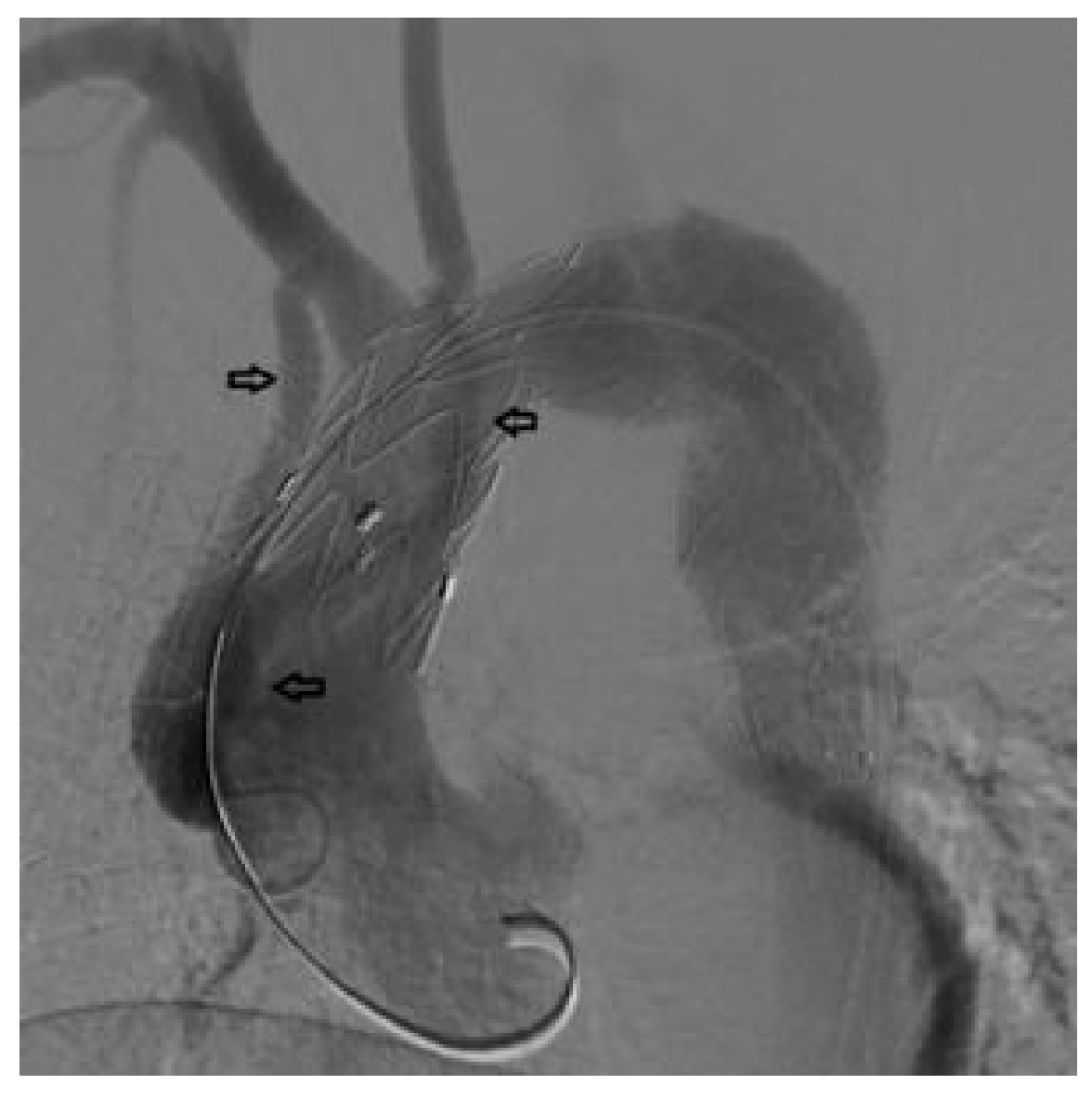

